\title{
Abnormal Adaptation of Visual Contrast Sensitivity In Multiple Sclerosis Patients
}

\author{
J. RAYMOND, D. REGAN, T.J. MURRAY
}

SUMMARY: Some multiple sclerosis patients with 20/20 acuity complain of poor vision. In a previous report we accounted for this in our patient group by showing that multiple sclerosis had caused a depression of contrast sensitivity while sparing visual acuity. In this study we investigated whether some of this measured depression might be due to abnormally rapid or severe adaptation during the test procedure rather than a true permanent loss. Our finding was opposite to this supposition: adaptation was abnormally slight and/or slow.

Depressed contrast sensitivity was not well correlated with abnormal adaptation to contrast. In patients whose contrast sensitivity losses were restricted to a band

RESUME: Plusieurs patients souffrant de sclérose en plaques et dont l'acuité visuelle est de 20/20 se plaignent néanmoins de mauvaise vision. Préalablement nous avions expliqué ce phénomène en démontrant chez nos patients une dépression de la sensibilité aux contrastes en labsence d'atteinte de l'acuité visuelle. Dans la présente étude nous investiguons la possibilité d'une adaptation anormalement rapide ou sévère lors du test d'évaluation, plutôt que celle d'une perte permanente réelle. Nos résultats nient cette hypothèse, démontrant plutôt une adaptation anormalement faible ou lente.

La dépression dans la sensibilité aux contrastes n'est pas en corrélation parfaite avec une adaptation arnormale $\dot{a}$ ces contrastes. Par exemple nous n'avons pas of spatial frequencies, we found no evidence that abnormalities of contrast adaptation were restricted to this same spatial frequency band. Further evidence of dissociation between abnormal contrast sensitivity and abnormal contrast adaptation is that some patients with normal contrast sensitivity showed abnormally small adaptation.

Our finding of abnormally slow or abnormally small contrast adaptation in MS patients seems to conflict with Enoch et al.'s (1978) report of abnormally great adaptation after inspecting a bright stimulus. This apparent disagreement may be due to their use of prior dark adaptation, very bright adapting stimuli and patients in the acute stage of retrobulbar neuritis.

trouvé d'évidence en faveur de troubles dans ladaptation aux contrastes limités à la même bande spatiale de fréquence que celle où sont localisées les pertes de sensibilité aux contrastes. Il existe d'autres évidences de la dissociation entre ces deux modalités, car certains patients à sensibilité aux contrastes normale, ont une adaptation anormalement basse.

Nos observations d'adaptation très lente ou très faible dans la sclérose en plaques semblent différer du rapport de Enoch et coll. (1978) qui trouvent une adaptation anormalement grande après un stimulus brillant. Cette divergence apparente résulte peut-être de l'emploi préalable d'adaptation à la noirceur, de stimulus adaptatoire très brillant et de patients en phase aigue de névrite rétrobulbaire.

\section{INTRODUCTION}

We previously reported that testing visual acuity (for example by means of the Snellen letter test or by measuring cutoff spatial frequency) can be an inadequate method of assessing vision in multiple sclerosis (MS) patients: a considerable proportion of patients, including those with normal Snellen acuity, have reduced contrast sensitivity at intermediate and/or low spatial frequencies. Some of these MS patients are able to see high spatial frequencies (and therefore fine detail) normally so that they can read the small letters of a Snellen chart. However, these same patients may be unable to see lower spatial frequencies of low contrast (i.e. coarser patterns) that are clearly seen by subjects with normal vision (Regan et al., 1977; Regan et al., 1981; Ginsburg, 1981; Zimmern, et al., 1979)'. Thus, a MS patient who can read the finest print at arm's length might have unusual difficulty seeing large objects such as buildings and automobiles in foggy weather. One practical clinical application of this contrast sensitivity test is its ability to demonstrate an organic basis for the complaints of patients whose visual disabilities seem to be more severe than would be expected on the grounds of Snellen acuity and visual fields.

It seems likely that contrast sensitivity losses are, at least in part, due to cortical pathology. The most direct

\footnotetext{
Footnote 1

Degraded contrast sensitivity is by no means restricted to MS. It has been associated with lesions to visual cortex (Bodis-Wollner, 1972: Bodis-Wollner and Diamond, 1976), with glaucoma (Arden and Jacobson. 1978 ) and with amblyopia (Hess. Howell and Kitchin. 1978; Ginsburg. 1980).
} 
evidence for this is that in some MS patients visual sensitivity to sinewave gratings of a particular orientation may be reduced (Regan et al., 1980) and that visual evoked responses to gratings of specific orientations may be delayed (Camisa et al., 1980).

However, we have an incomplete understanding of the patho-physiological basis of depressed contrast sensitivity in MS. In particular, previous reports left unanswered the question of whether the observed sensitivity losses might in some degree be an artifact of abnormally severe or rapid adaptation to the grating patterns used in the test procedure.

In this study, we investigated whether MS patients' contrast thresholds rose abnormally severely or rapidly after viewing high-contrast grating patterns. Our chief finding was the opposite to what we had expected: adaptation was less effective in producing elevations of contrast threshold in MS patients than in control subjects.

\section{METHODS}

\section{Patients and control subjects}

Patients were diagnosed according to the criteria set out by Schumacher et al. (1968), and were classified according to the disability scale of Kurtzke
(1965). Clinical data for all patients are listed in Table 1. The control subjects all had corrected visual acuity of 20/40 or better and none had any history of neurological disorder affecting the visual system. Patients' ages ranged from 21 to 55 years while control subjects' were 18 to 53 years. 8 males and 13 females were in the patient group; 13 males and 22 females in the control group. The patient group was subdivided into two: Ten patients had no visual indications of MS (MS no VI group) while 11 patients showed visual indications (MS VI group). Visual indications included pale discs, clinically evident nystagmus, corrected Snellen acuity worse than $20 / 40$, or a history of retrobulbar neuritis (RBN).

\section{Apparatus}

In most experiments we used sinusoidal gratings generated by conventional means (Schade, 1956; Campbell \& Green, 1965) on the face of a Tektronix 604 CRT (phosphor type 31). In some experiments requiring high luminance, we used a grating stimulator made by Joyce of Cambridge. In all cases the same stimulator was used for adaptation experiments and measurements of the contrast sensitivity function. During adaptation periods the positions of the light and dark bars alternated 3 times per second. This was done in an attempt to avoid creating afterimages of the bright and dark bars.

The subject was seated $171 \mathrm{~cm}$ from the stimulus screen at a table of variable height equipped with a chin rest and enclosing screen and viewed the CRT face and white adapting surround through a hole in the screen. The CRT face was circular and $9.5 \mathrm{~cm}$ $\left(3.2^{\circ}\right.$ of visual angle) in diameter. The surround extended out to a radius of $10^{\circ}$. The mean luminance of the Tektronix CRT was $29 \mathrm{~cd} / \mathrm{m}^{2}$ for all stimulus conditions and the mean luminance of the Joyce CRT was 130 $\mathrm{cd} / \mathrm{m}^{2}$. The luminance of the surround was $545 \mathrm{~cd} / \mathrm{m}^{2}$. Viewing conditions using either CRT were identical except for the mean luminance of the CRT face. The brightly lit surround was intended to hold the state of light adaptation of the subject's eye at a constant, high photopic level.

Snellen acuity was measured conventionally at a distance of 20 feet.

Procedure: definition of contrast threshold elevation

We measured contrast sensitivity by the method of adjustment, that is, we instructed subjects to adjust the contrast on the screen until they could just see the grating. Contrast threshold measured in this way is elevated by

\begin{tabular}{|c|c|c|c|c|c|c|c|c|}
\hline Patient & Age & Sex & Diagnosis & Onset & $\begin{array}{l}\text { Kurtzke } \\
\text { Scale } \\
\end{array}$ & Visual Indications & $\begin{array}{c}\text { Snellen } \\
\text { L }\end{array}$ & $\begin{array}{c}\text { Acuity } \\
\mathbf{R}\end{array}$ \\
\hline 1 & 32 & $f$ & definite MS & 1978 & 2 & none & $20 / 40$ & $20 / 30$ \\
\hline 2 & 43 & $\mathrm{~m}$ & possible MS & 1979 & I & none & $20 / 30$ & $20 / 30$ \\
\hline 3 & 21 & $\mathrm{~m}$ & definite MS & 1977 & 1 & none & $20 / 30$ & $20 / 20$ \\
\hline 4 & 29 & $\mathrm{f}$ & definite MS & 1974 & 2 & none & $20 / 20$ & $20 / 30$ \\
\hline 5 & 53 & $\mathrm{f}$ & definite MS & 1979 & 1 & none & $20 / 20$ & $20 / 20$ \\
\hline 6 & 42 & $\mathrm{f}$ & definite MS & 1979 & 2 & none & $20 / 20$ & $20 / 20$ \\
\hline 7 & 32 & $f$ & definite MS & 1972 & 1 & none & $20 / 20$ & $20 / 20$ \\
\hline 8 & 34 & $\mathrm{~m}$ & definite MS & 1976 & 3 & none & $20 / 20$ & $20 / 20$ \\
\hline 9 & 41 & $\mathrm{f}$ & definite MS & 1968 & 7 & none & $20 / 20$ & $20 / 20$ \\
\hline 10 & 53 & $\mathrm{f}$ & definite MS & 1972 & 3 & none & $20 / 20$ & $20 / 20$ \\
\hline 11 & 50 & $\mathrm{~m}$ & definite MS & 1974 & 1 & rt internuclear ophthalmoplegia & $20 / 30$ & $20 / 20$ \\
\hline 12 & 40 & f & definite MS & 1977 & 1 & left disc pallor & $20 / 20$ & $20 / 20$ \\
\hline 13 & 30. & $\mathrm{~m}$ & definite MS & 1978 & 2 & pale discs bilaterally & $20 / 30$ & $20 / 20$ \\
\hline 14 & 45 & $\mathrm{~m}$ & definite MS & 1978 & 1 & pale discs bilaterally & $20 / 30$ & $20 / 20$ \\
\hline 15 & 21 & $\mathrm{f}$ & definite MS & 1978 & 2 & left optic neuritis & $20 / 15$ & $20 / 20$ \\
\hline 16 & 55 & $\mathrm{~m}$ & definite MS & 1965 & 3 & left optic neuritis & $20 / 20$ & $20 / 20$ \\
\hline 17 & 47 & $\mathrm{f}$ & definite MS & 1967 & 3 & pale discs bilaterally & $20 / 30$ & $20 / 30$ \\
\hline 18 & 24 & f & definite MS & 1978 & 1 & ataxic nystagmus & $20 / 80$ & $20 / 30$ \\
\hline 19 & 24 & $f$ & definite MS & 1972 & 2 & optic neuritis bilaterally & $20 / 60$ & $20 / 40$ \\
\hline 20 & 23 & f & definite MS & 1977 & 2 & right optic neuritis & $20 / 30$ & $20 / 20$ \\
\hline 21 & 56 & $\mathrm{~m}$ & probable MS & 1979 & 1 & rt internuclear ophthalmoplegia & $20 / 20$ & $20 / 20$ \\
\hline
\end{tabular}

Table 1 -Clinical details of patients. 
inspecting a high contrast grating of the same spatial frequency and orientation as the test grating (Gilinsky, 1968; Pantle and Sekuler, 1968; Blakemore and Campbell, 1969). However, threshold elevation is not necessarily all due to contrast adaptation since contrast threshold is also elevated by inspecting an unpatterned field. We attempted to extract the adapting effect of light alone from the adapting effect of light + contrast by assuming that the two log threshold elevations add linearly, defining threshold elevation due to grating adaptation alone as equal to $T_{P}-T_{U}$ where $T_{P}$ and $T_{U}$ were respectively the thresholds after adapting to a patterned and to an unpatterned field, both expressed in log units. In preliminary experiments on four MS patients and three control subjects we found that thresholds taken 100 seconds or more after adaptation to a high contrast pattern were the same as those taken at any time after adaptation to a blank screen. In subsequent experiments, we took the baseline contrast threshold as the mean of all contrast thresholds taken 100 seconds or more after adaptation to the patterned screen and thus eliminated the lengthy control procedure of adapting to a blank screen.

\section{Psychophysical procedure}

In most adaptation experiments, a single adaptation period was followed by a series of test intervals spaced 10 or 20 seconds apart allowing 5 seconds for a setting. We repeated this sequence three times for each adaptation condition in each experiment and the presentation order of different conditions was random. Unless otherwise stated, the adapting pattern was a $70 \%$ contrast $7 \mathrm{c} / \mathrm{deg}$ sinewave grating which phase-reversed 3 times per second. The test stimulus was always of the same spatial frequency as the adapting pattern.

To maximize the use of thresholds taken several seconds after adaptation, we fitted a straight line to each set of $\log$ threshold elevations ( $y$ axis) and plotted versus time (linear $x$ axis) measured after termination of the adapting pattern. The y-intercept of this line was then used as an estimate of the size of the maximum threshold elevation.

\section{Experiment I}

We presented a $7 \mathrm{c} / \mathrm{deg} 70 \%$ contrast adaptation pattern for 20,60 or 120 seconds and measured contrast thresholds immediately following the end of the adaptation period and every 10 seconds thereafter until 3 minutes had elapsed. A blank screen was presented between the 5-second test intervals.

Eight MS-VI patients, five MS-noVI patients and 16 normal control subjects were tested in at least one eye at all three adaptation durations. We tested an additional four MS patients and three normal controls using only 60 seconds of adaptation.

\section{Experiment 2}

Grating patterns of 1,7 or $12 \mathrm{c} / \mathrm{deg}$ were each presented as adapting stimuli at four different contrasts. All adaptation periods were 60 seconds in length. We measured contrast thresholds immediately following the end of the adaptation period and every 10 seconds thereafter. A blank screen was presented between the 5-second test intervals. Four MS-VI, 2 MS-no-VI patients and 7 normal control subjects were tested using a $7 \mathrm{c} /$ deg pattern, 2 MS-VI, 1 MS-no-VI patients, and 5 normal controls with a $1 \mathrm{c} / \mathrm{deg}$ pattern, and 2 MS-VI, I MS-no-VI patient and 6 normal controls with a 12 c/deg pattern.

Contrast thresholds were measured at seven different spatial frequencies (namely $0.5,1,3,5,7,12$ and $15 \mathrm{c} / \mathrm{deg}$ ) in both eyes in a single session using the method of limits. Four ascending and four descending trials were given for each spatial frequency tested, and the eye used was alternated after the contrast threshold for each spatial frequency was estimated. Five MS patients and nine normal subjects were tested.

\section{Experiment 3}

We presented an adapting pattern of $7 \mathrm{c} / \mathrm{deg}$ and $70 \%$ contrast for a total of 5 minutes interrupting the high contrast pattern every 20 seconds with the presentation of a 5-second test interval. Immediately afterwards the subjects viewed a blank screen for 2 minutes. We then presented another five test intervals, each spaced 10 seconds apart with a blank screen presented in between. Both eyes were tested sequentially within a single session. As baseline contrast threshold we took the mean of the last five thresholds. We repeated this experiment using a high-brightness CRT with a mean luminance of $130 \mathrm{~cd} / \mathrm{m}^{2}$. Three MS-VI patients, 2 MS-no-VI patients and 8 normal control subjects participated in the experiment using the lower brightness CRT. A subset of this group consisting of $3 \mathrm{MS}-\mathrm{VI}, 1$ MS-no-VI and 5 normal controls participated in the high luminance experiment.

\section{RESULTS \\ Contrast threshold elevation and decay}

In control subjects, log contrast threshold fell proportionally with time when adaptation was stopped, and approximated its final level after about 30-60 second recovery period. These results agree with those reported by Blakemore and Campbell (1969). Figure 1 shows that this time course held for patients as well as control subjects.

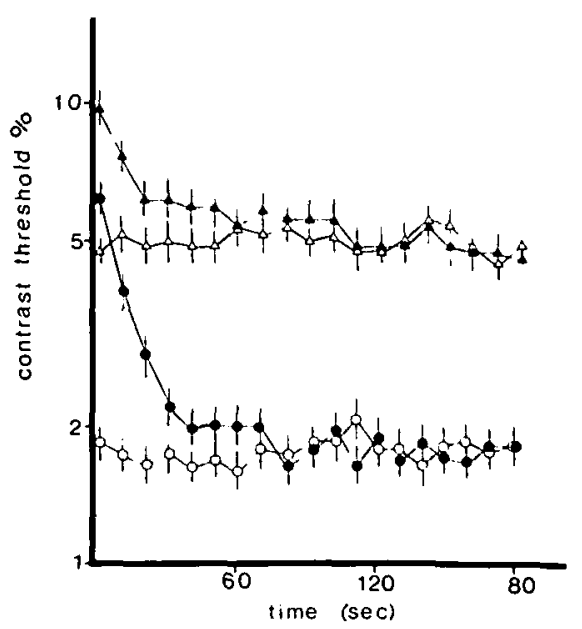

Figure 1-Decay of adaptation to contrast. Mean \% contrast thresholds for a group of four MS patients (triangles) and a group of three control subjects (circles) as a function of time after adapting for 1 minute to either a blank screen (open symbols) or a high contrast $7 \mathrm{c} / \mathrm{deg}$ sinewave grating pattern (closed symbols). Vertical lines indicate \pm I S.D. of the mean. The $y$-axis is logarithmic and the $\mathrm{x}$-axis is linear. 

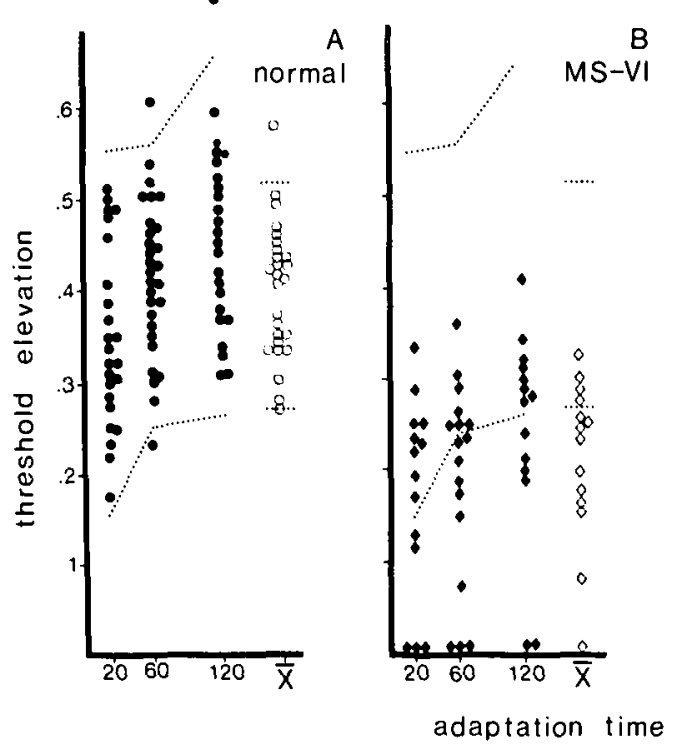
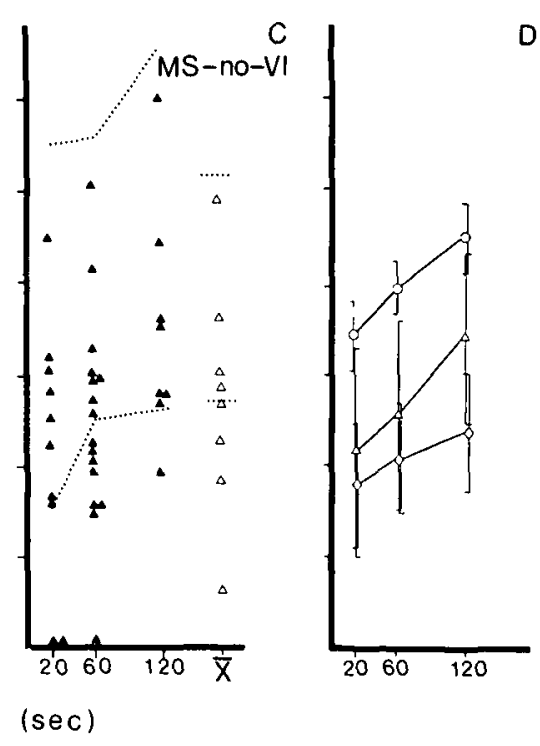

of individuals with similar baseline thresholds in Experiment 1 and, (b) by comparing threshold elevations in MS patients and control subjects in Experiment 2 where the use of different contrasts in the adaptation pattern allowed for the different baselines.

Figure 3 shows threshold elevations immediately after 60 seconds of adaptation for each eye of each subject in Experiment 1, plotted as a function of the baseline contrast threshold.

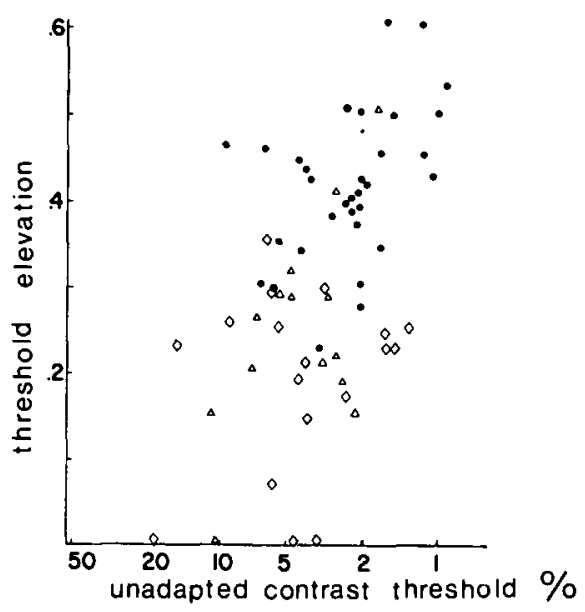

Figure 3-Threshold elevations recorded immediately after 1 minute adaptation for each individual plotted as a function of their own baseline contrast threshold. Both axes are logarithmic. Filled circles indicate control subjects, open diamonds represent MS-VI patients, and open triangles indicate MS-no-VI patients..

It is clear from the figure that over the $1 \%$ to $10 \%$ range of baseline contrast thresholds for which normal and MS subjects overlapped, the threshold elevations in the MS patients were consistently lower than the normal controls.

For six patients and eight control subjects we also plotted the maximum threshold elevations versus the difference between the contrast of the adapting pattern and the subject's baseline contrast. Compared with control subjects, the MS patients generally required a greater relative contrast in the adapting pattern to produce a given threshold elevation. For the three normal controls tested with adapting patterns less than $0.4 \mathrm{log}$ unit above their own unadapted threshold, small threshold elvations 
were still observed. On the other hand, for some MS patients, adapting patterns as much as 1.0 log units above the unadapted threshold were insufficient to induce a threshold elevation that was measurable in size.

It should be noted that abnormal adapatation was observed in some patients with normal baseline contrast sensitivity. In particular, three MS patients with distinctly abnormal adaptation effects had baseline contrast thresholds well within the normal range, although the MS patients as a group had baseline contrast thresholds well above those of the normal subjects.

\section{The contrast sensitivity function and contrast adaptation}

We measured complete contrast sensitivity functions in five MS patients and in nine normal control subjects. (The contrast sensitivity function is a plot of contrast threshold versus grating spatial frequency.) We then calculated mean contrast thresholds and standard deviations (S.D.s) for the control group, and compared contrast functions for individual patients with this mean curve. Thresholds more than 1.96 S.D. higher than the control mean were taken as abnormal ( $95 \%$ confidence level). We looked for patients who had a contrast sensitivity loss restricted to a limited range of spatial frequencies. Two of the MS patients had clear unilateral mid-spatial frequency contrast sensitivity losses at intermediate spatial frequencies. One loss was large in one eye ( $1.0 \log$ unit) and this was highly significant when compared with our present and previous control data. The interocular difference $(0.6 \mathrm{log}$ unit) was also abnormal in terms of present and previous control data. Similar remarks apply to the other subject's intermediate spatial frequency loss (0.7 log unit in one eye, $0.7 \log$ unit interocular difference). A third patient had a less marked bilateral intermediate frequency loss of $0.5 \log$ unit. A fourth patient had a unilateral low spatial frequency loss in one eye (absolute loss and interocular difference about 0.5 $\log$ units).

We examined the effect of adapting pattern contrast upon threshold elevations for different spatial frequencies in these four patients and in six normal controls using the procedure described in Experiment 2 and using at least two spatial frequencies for each individual and four adapting contrasts for each spatial frequency.

Our finding of little or no threshold elevation with adapting patterns of low relative contrast seen in the MS patients for $7 \mathrm{c} / \mathrm{deg}$ patterns was repeated when a 1 or $12 \mathrm{c} / \mathrm{deg}$ grating pattern was used. Some MS patients failed to show evidence of adaptation even when the adapting pattern was between 0.4 and $1.0 \mathrm{log}$ unit above their unadapted threshold, whatever the spatial frequency. This also held for patients who showed no sensitivity losses for the particular spatial frequency used.

Although patient $\# 15$ had a history of retrobulbar neuritis in her left eye only, she showed a sensitivity loss in the right eye for spatial frequencies below $7 \mathrm{c} / \mathrm{deg}$. The left eye had normal contrast vision. Threshold elevations for a low spatial frequency pattern (1 $\mathrm{c} / \mathrm{deg}$ ) using the right eye were smaller than any of the $1 \mathrm{c} / \mathrm{deg}$ control threshold elevations. Those obtained with her left eye were of normal magnitude. Threshold elevations obtained using 7 and $12 \mathrm{c} /$ deg patterns required a larger relative adapting pattern contrast than controls, whichever eye was used. Thus, for this patient, in the eye that had the low spatial frequency loss, adaptation effects were abnormal for all spatial frequencies studied. The eye with normal contrast sensitivity at all spatial frequencies had slightly abnormal adaptation functions only at high spatial frequencies.

Patient $\# 17$ had a severe medium spatial frequency loss in her left eye only, but had bilaterally pale discs. Abnormally small threshold elevations were found at all spatial frequencies tested (i.e. 1 and $7 \mathrm{c} / \mathrm{deg}$ ) when either eye was used.

Patient $\# 20$ had a slight bilateral medium spatial frequency loss in both eyes and a history of RBN in her right eye. She showed abnormally small threshold elevations with her right eye when tested with 7 or $12 \mathrm{c} / \mathrm{deg}$ patterns. Threshold elevations obtained with her left eye were normal. Patient \#11 (MS-no-VI) had a contrast threshold difference of $0.7 \log$ unit in his right eye at $12 \mathrm{c} / \mathrm{deg}$ and normal contrast sensitivity at all other spatial frequencies. Threshold elevations obtained using his right eye at both 12 and $1 \mathrm{c} / \mathrm{deg}$ were smaller than those obtained with his left eye and smaller than normal.

\section{Buildup of adaptation to contrast}

In the next experiment we measured the buildup of threshold elevations over a 5-minute period of adaptation.

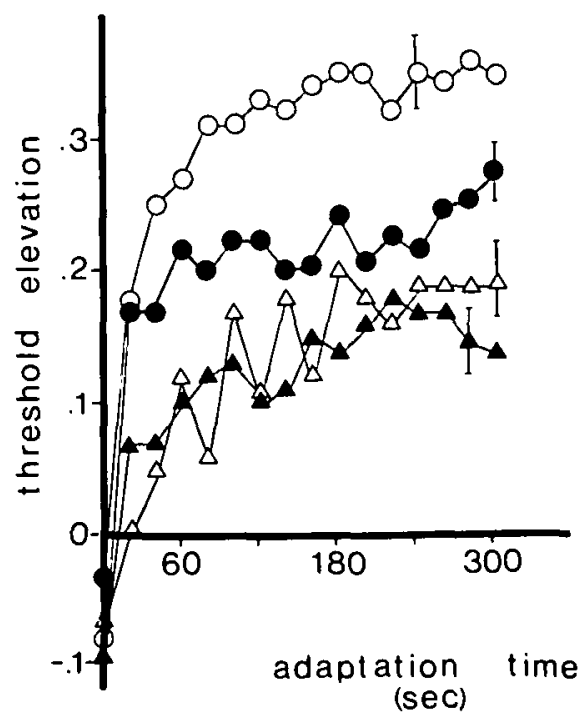

Figure 4-Buildup of adaptation to contrast. Mean threshold elevations (in log units) are shown as a function of adaptation duration for five MS patients and four control subjects. Measurements made using a grating of $29 \mathrm{~cd} / \mathrm{m}^{2}$ mean luminance are represented by closed symbols and those made using the 130 $\mathrm{cd} / \mathrm{m}^{2}$ pattern are shown by open symbols. The control group is represented by circles and the MS group by triangles. Vertical lines indicate \pm 1 S.E.

Figure 4 shows that threshold elevations for the 8 control subjects rose quickly in the first $20-80$ seconds and then increased more gradually over the next 4 minutes adaptation. This agrees with Blakemore and Campbell's (1969) report that the adaptation effect reaches a plateau after about 60 seconds (see also Bodinger [1978]). Results for the 5 MS patients were quite different. They showed a continuous gradual increase 
in threshold elevation throughout the first 3 minutes of adaptation. Stimulus luminance had no effect on either baseline contrast thresholds or threshold elevation for the MS group. The shapes of the buildup curves were not substantially altered by the change in luminance. Individual data showed that the size of the maximum threshold elevation (after 4 minutes of adaptation) was higher if the baseline contrast threshold was low. In brief, MS patients with the same unadapted contrast thresholds as normal subjects eventually attained the same threshold elevations as control subjects, but took up to four times the duration of adaptation to reach the normal elevations. Figure 5A illustrates this, showing examples of one MS patient and one normal with matched baseline contrast thresholds.

Figure 5B shows the buildup of threshold elevations for a single MS patient $(\# 20)$ whose baseline contrast thresholds in the two eyes differed by only $0.14 \log$ unit. This patient had a history of optic neuritis in the right eye and it can be seen in the figure that threshold elevations using the right eye

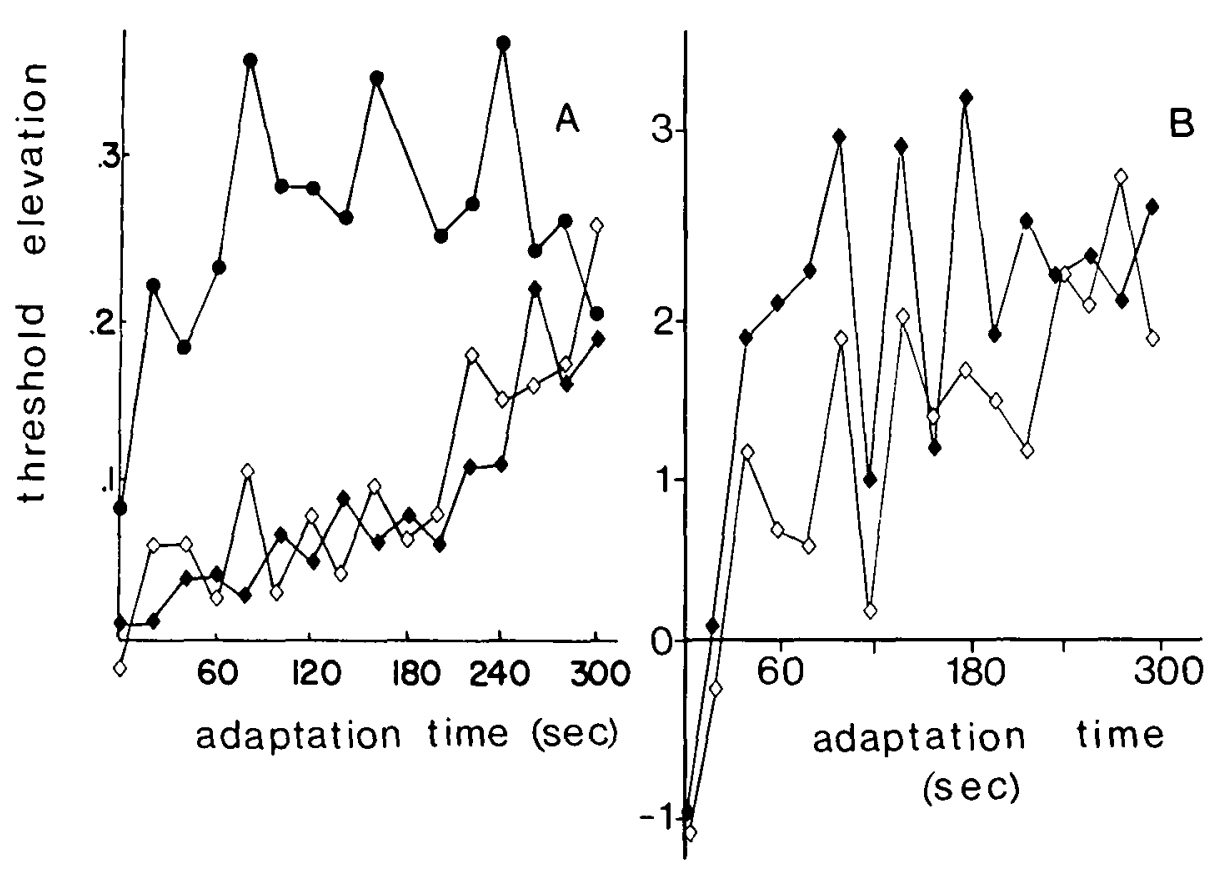

Figure 5-Buildup of threshold elevations in an MS patient and a control subject with the same unadapted contrast threshold. The control subject's data are shown by closed circles and the MS patient's by squares.

B - Buildup of threshold elevations in each eye of an MS patient with a history of optic neuritis in the right eye. The right eye is indicated by open symbols and the left eye by closed symbols. built up slowly during the first few minutes of adaptation, while the left eye attained its maximum threshold elevation after only 60 seconds of adaptation. Thus, her affected eye required approximately four times the duration of exposure to the high contrast pattern as her unaffected eye to produce a similar threshold elevation.

\section{DISCUSSION}

Are measured losses of contrast sensitivity in multiple sclerosis an artifact of abnormally rapid and/or severe adaptation of contrast sensitivity?

Our initial reason for undertaking this study was to define the extent to which abnormally rapid and/or severe adaptation of contrast threshold might account for previous reports that baseline contrast sensitivity is depressed in many multiple sclerosis patients. In these earlier studies, subjects intermittently viewed grating patterns during a test period of up to 1.5 hours. MS patients, unlike normal subjects, might have experienced contrast adaptation under these conditions which could have caused erroneously low estimates of baseline contrast sensitivity. In order to compare contrast sensitivity with contrast adaptation measures we have now measured both contrast sensitivity and contrast adaptation using the same field size and mean luminance. ${ }^{2}$

We considered a possible confounding factor, namely that many MS patients are less sensitive to contrast than control subjects, and for this reason alone an adapting grating of given contrast might be less effective with an MS patient than with a control subject. We allowed for this point by using adapting gratings that were a fixed number of $\log$ units above unadapted threshold. Thus, some MS patients adapted to gratings of higher contrast than those viewed by control subjects.

Even so, our finding was opposite to that anticipated: Threshold elevations produced by inspecting a grating of given contrast for 20-60 seconds were smaller for MS patients than for controls. Expressed this way however, our finding is somewhat misleading. When, in a subsidiary experiment on four patients, we monitored contrast thresholds over a longer period of adaptation, it became clear that, for three of four patients, the difference between MS patients and controls was better expressed by saying that MS patients adapted more slowly than control subjects, rather than, contrast thresholds were less elevated by adaptation in MS patients, though one patient did show negligible adaptation even after 5 minutes adaptation.

We conclude that contrast sensitivity losses reported in MS patients are not due to abnormally large or rapid elevations of contrast threshold during the test procedure.

Are abnormalities of adaptation restricted to spatial frequencies for which contrast sensitivity is reduced?

Some MS patients experience losses of contrast sensitivity that are

\footnotetext{
Footnote 2

This mean luminance, in the low photopic range, was typical of the luminance of test gratings used in many laboratories. Its rather low value is a consequence of setting the commonly-used models of CRT to the middle of the linear range.
} 
restricted to a narrow band of spatial frequencies (Regan et al., 1977; Zimmern et al., 1979). Taken together with evidence that the visual pathway analyzes the retinal image into restricted bands of spatial frequencies (Campbell and Robson, 1968; Blakemore and Campbell, 1968; Robson, 1975 ) this finding led us to ask whether abnormalities of adaptation were restricted to the same band of spatial frequencies as sensitivity losses. We would expect this if disordered sensitivity and adaptation were two aspects of the same physical damage to one or more narrow band width spatial frequency mechanism.

On the contrary, we found that threshold elevations caused by adaptation were abnormally small for all spatial frequencies. This was so even when contrast sensitivity losses were restricted to a narrow band of spatial frequencies. This conclusion held whether or not we allowed for the elevated baseline contrast thresholds observed in MS patients.

\section{Contrast adaptation at high luminance levels}

Enoch et al., (1978) reported that, after a 0.5-1.5 minute exposure to a bright red grating stimulus of high spatial frquency, multiple sclerosis patients experienced an abnormally severe loss of visual acuity that could be as large as tenfold. As reported above, we were unable to confirm this finding. With the aim of defining the reason for this disagreement we carried out further experiments on a small group of four patients and five controls. Our visual stimuli differed in several ways from those used by Enoch et al. For example, the mean luminance of our adapting field was about five times less than the dimmest adapting field used by Enoch et al. (whose luminances ranged from about $10^{2}$ $\mathrm{cd} / \mathrm{m}^{2}$ to $\left.10^{4} \mathrm{~cd} / \mathrm{m}^{2}\right)$. We repeated some of our adaptation measurements with the brightest CRT grating stimulator we were able to obtain. This device had a mean luminance of 130 $\mathrm{cd} / \mathrm{m}^{2}$, so that this field was approximately as bright as the dimmest of the laser-generated stimuli used by Enoch et al. However, even with this device, contrast threshold elevations were smaller in MS patients than in normals. Therefore, insufficient luminance is probably not the reason our findings were opposite to Enoch et al.'s. Possible, alternative explanations not explored are that Enoch et al. allowed an initial 5-minute period of dark adaptation while we worked with a constant photopic level of light adaptation; they measured visual acuity (i.e. visual sensitivity at high spatial frequencies), while we measured contrast sensitivity at lower spatial frequencies; they used far red monochromatic stimuli while our gratings were green.

Whether or not the MS patients are in the acute stage of RBN or in remission may also be a factor. We attempted to study two additional patients in the acute stage of RBN, and although our measurements were fragmentary we had the impression that these patients did show abnormally rapid and severe elevations of contrast threshold.

\section{ACKNOWLEDGEMENTS}

This work was supported by the Medical Research Council of Canada (Grant MA-6495), the National Eye Institute (Grant IROI-EY03058-0I) and the Multiple Sclerosis Society of Canada. J. Raymond was supported by a scholarship from the Natural Sciences and Engineering Research Council of Canada.

We are grateful to Dr. David King for allowing us to study patients in his care.

\section{REFERENCES}

ARDEN, D.B. and JACOBSEN, J.J. (1978). A simple grating test for contrast sensitivity: preliminary results indicate value for screening in glaucoma. Investigative Ophthalmology and Visual Science, 17, 23.

BLAKEMORE, C. and CAMPBELL, F.W. (1968). On the existence of neurones in the human visual system selectively sensitive to the orientation and size of retinal images. Journal of Physiology (London), 203, 237260.

BODINGER, D.M. (1978). The decay of grating adaptation. Vision Res., 18, 89-91.

BODIS-WOLLNER, I. (1972). Visual acuity and contrast sensitivity in patients with cerebral lesions. Science, 178, 769-771.
BODIS-WOLLNER, I. and DIAMOND, S.P. (1976). The measurement of spatial contrast sensitivity in cases of blurred vision associated with cerebral lesions. Brain, 99 , 695-710.

CAMISA, J.M., MYLIN, L.H. and BODISWOLLNER, I. (1980). Meridional visual evoked potential latency changes in multiple sclerosis. Annals of Neurology, in press.

CAMPBELL, F.W. and GREEN, D.G. (1965). Optical and retinal factors affecting visual resolution. Journal of Physiology (London), 207, 635-652.

CAMPBELL, F.W. and ROBSON, J.G. (1968). Application of Fourier analysis to the visibility of gratings. Journal of Physiology (London), 197, 551-566.

ENOCH, J.J., CAMPOS, E.C., GREER, M. and TROBE, J. (1978). Measurement of visual resolution at high luminance levels in patients with possible demyelinating disease. Proceedings of the International Ophthalmology and Optics Symposium, Tokyo, pp. 67-72.

GILINKSY, A. (1968). Orientation specific effects of patterns of adapting light on visual acuity. Journal of the Optical Society of America, 58, 13-18.

GINSBURG, A.P. (1981). Spatial filtering and vision: Implications for normal and abnormal vision. Presented at the Symposium on Applications of Psychophysics to Clinical Problems, San Francisco. In press.

HESS, R.F., HOWELL, E.R. and KITCHIN, J. E. (1978). On the relationship between pattern and movement detection in strabismic amblyopia. Vision Research, 18, 375-377.

KURTZKE, J.F. (1965). On the evaluation of disability in multiple sclerosis. Neurology, 15, 654 .

PANTLE, A. and SEKULER, R. (1968). Size detecting mechanisms in human vision. Science, 162, 1146-1148.

REGAN, D., SILVER, R. and MURRAY, T.J. (1977). Visual acuity and contrast sensitivity in multiple sclerosis: Hidden visual loss. Brain, 100, 563-579.

REGAN, D., RAYMOND, J., GINSBURG, A. and MURRAY, T.J. (1981). Contrast sensitivity, visual acuity and the discrimination of Snellen letters in multiple sclerosis. Brain, in press.

REGAN, D., WHITLOCK, J.A., MURRAY, T.J. and BEVERLEY, K.I. (1980). Orientation-specific losses of contrast sensitivity in multiple sclerosis. Investigative Ophthalmology and Visual Science, 19, 324328.

ROBSON, J.G. (1975). Receptive fields: Neural representation of the spatial and intensive attributes of the visual image. In E.C. Carterette and M.P. Friedman (Eds.), Handbook of perception. Vol. V (Seeing). New York: Academic Press, pp. 81-116.

SCHADE, O.H. (1956). Optical and photoelectric analog of the eye. Journal of the Optical Society of America, 46, 721-739. 
SCHUMACHER, G.A., BEEBE, G. and KILBER, R.E. (1968). Problems of experimental trials of therapy in MS. Report of the panel on evaluation of experimental trials in MS. Annals of the N.Y. Academy of Science, 122, 522.

ZIMMERN, R.L., CAMPBELL, F.W. and WILKINSON, I.M.S. (1979). Subtle disturbances of vision after optic neuritis elicited by studying contrast sensitivity. J. Neurol. Neurosurg. Psychiat., 42, 407-412. 